\title{
Resíduo da extração de própolis como inibidor bacteriano in vitro
}

\author{
Propolis extraction residue like bacterial inhibitor "in vitro"
}

\author{
HEIMBACH, Natália da Silva ${ }^{1}$; ÍTAVO, Camila Celeste Brandão Ferreira ${ }^{1}$; LEAL, \\ Cássia Rejane Brito ${ }^{1}$; ÍTAVO, Luís Carlos Vinhas ${ }^{1 *}$; SILVA, Jonilson Araújo da ${ }^{1}$; \\ SILVA, Pâmila Carolini Gonçalves ${ }^{1}$; REZENDE, Letícia Costa de ${ }^{1}$; GOMES, Maria de \\ Fátima Falcão ${ }^{1}$
}

\author{
${ }^{1}$ Universidade Federal do Mato Grosso do Sul, Faculdade de Medicina Veterinária e Zootecnia, Campo \\ Grande, Mato Grosso do Sul, Brasil.. \\ *Endereço para correspondência: luis.itavo@ufms.br
}

\section{RESUMO}

Objetivou-se avaliar o efeito dos resíduos da extração hidroalcoólica de própolis dos tipos verde e marrom sobre o desenvolvimento de bactérias Gram-positivas e Gram-negativas. As própolis brutas foram adquiridas da apicultura "Companhia da Abelha", instalada em Contagem, Minas Gerais. A própolis verde foi derivada de "alecrim-do-campo" (Baccharis dracunculifolia), e a própolis marrom foi derivada de "alecrim-do-campo" (B. dracunculifolia) e "assa-peixe" (Vernonia polyanthes). Foram usados cinco níveis de inclusão $(0 ; 0,625 ; 0,125 ; 0,25 ; 0,5 \mathrm{~g})$ dos resíduos, além do controle para o inóculo (CI), e seis amostras bacterianas, sendo duas delas Gram-positivas e quatro Gram-negativas. O método utilizado foi o de contagem de unidades formadoras de colônias em placas de petri (pour plate). Entre as bactérias Gram-positivas, o maior efeito inibidor foi detectado para amostras de Staphylococcus aureus, e maior susceptibilidade foi para a Escherichia coli dentre as Gram-negativas. Houve efeito antimicrobiano do resíduo da extração da própolis verde sobre as bactérias $S$. aureus e $S$. intermedius. O resíduo da extração da própolis marrom apresentou maior inibição para $S$. intermedius somente nos tratamentos com $0,5 \mathrm{e}$ $0,25 \mathrm{~g}$ de resíduo. Não houve efeito do resíduo da extração de própolis verde ou marrom sobre o crescimento de bactérias gênero Pseudomonas. Os resíduos da extração hidroalcoólica de própolis verde e marrom atuaram como inibidores de crescimento das bactérias Staphylococcus aureus,
Staphylococcus intermedius e Escherichia coli, e em menor grau para Salmonella e Klebsiella. $\mathrm{O}$ resíduo tem maior efeito inibidor em bactérias Gram-positivas.

Palavras-chave: efeito antimicrobiano, Gramnegativa, Gram-positiva

\section{SUMMARY}

This study aimed to evaluate the effect of residues extraction hydroalcoholic of propolis, green and brown, on the development of Grampositive and Gram-negative bacteria. The crude propolis was obtained from "Companhia da Abelha" in Contagem, Minas Gerais. The green propolis derived from "alecrim-do-campo" (Baccharis dracunculifolia), and the brown propolis derived from "alecrim-do-campo" $(B$. dracunculifolia) and "assa-peixe" (Vernonia polyanthes). We used five levels of inclusion ( 0 ; $0.625 ; 0.125 ; 0.25 ; 0.5 \mathrm{~g})$ of the residue, and control for the inoculum (CI) and six bacterial strains, two of which are Gram-positive and four Gram-negative. The method used was to count colony-forming units in petri dishes (pour plate). Among the Gram-positive bacteria, the greatest inhibitory effect was detected for Staphylococcus aureus strains, and increased susceptibility was observed for Escherichia coli among Gram-negative bacteria. There was antimicrobial effect of the residue of the propolis extract on $S$. aureus and $S$. intermedius. The residue of brown propolis extract showed greater inhibition for $S$. intermedius only in 0.5 and $0.25 \mathrm{~g}$ of residue inclusion levels. There was 
no effect of residues extraction hydroalcoholic of propolis, green and brown on the growth of Pseudomonas. The residues of the extraction of propolis green and brown acted as inhibitors of growth of Staphylococcus aureus, Staphylococcus intermedius and Escherichia coli, and to a lesser extent Salmonella and Klebsiella. The residue has greater inhibitory effect on Gram-positive bacteria.

Keywords: antimicrobial effect, Gramnegative, Gram-positive

\section{INTRODUÇÃO}

A própolis é originada de substâncias gomosas, balsâmicas e resinosas, colhida pelas abelhas, de brotos, flores e exsudatos de plantas, nas quais as abelhas depositam secreções salivares, cera e pólen. A própolis tem sido amplamente utilizada devido às propriedades atribuídas ao produto, como atividade antioxidante (PARK et al., 1998), antifúngica (LONGHINI et al., 2007) e antimicrobiana (GONSALES et al., 2006), as quais estão relacionadas com a composição química, influenciada pela florada na qual as abelhas buscam o substrato para fazer a própolis. De acordo com Mirzoeva et al. (1997), a própolis exerce ação bacteriostática sobre bactérias Gram-positivas e algumas Gram-negativas, aparentemente pela modificação do status bioenergético da membrana bacteriana e inibição de sua motilidade, o que remete à atividade dos ionóforos. $\mathrm{O}$ extrato etanólico de própolis como aditivo na alimentação de animais tem melhorado a conversão e eficiência alimentar de cordeiros (ÍTAVO et al., 2011) e resultado em maior ganho de peso, menor mortalidade e melhor eficiência alimentar em pintinhos (SHALMANY \& SHIVAZAD, 2006). Vargas et al. (2004), observaram que o extrato alcoólico de própolis a $50 \%$ apresentou atividade antibacteriana in vitro inibindo o crescimento de $67,70 \%$ das amostras de bactérias em líquido ruminal.

A partir da própolis bruta, faz-se a extração etanólica. Após essa etapa, o extrato representa apenas $10 \%$ da própolis, sendo que a maior parte $(90 \%)$ constitui-se como o resíduo, que muitas vezes é descartado no meio ambiente, sem ter uma forma de aplicação pesquisada. Nesse sentido, objetivou-se avaliar a ação inibitória in vitro dos resíduos da extração hidroalcoólica da própolis verde e marrom sobre o desenvolvimento de bactérias Grampositivas e Gram-negativas, visando a utilização deste produto como aditivo na alimentação de ruminantes com o intuito de melhorar o desempenho e resposta animal.

\section{MATERIAL E MÉTODOS}

O experimento foi conduzido nas dependências da Faculdade de Medicina Veterinária e Zootecnia da Universidade Federal de Mato Grosso do Sul - UFMS, em Campo Grande-MS. As própolis brutas foram adquiridas da apicultura Companhia da Abelha, instalada em Contagem, Minas Gerais, sendo a própolis verde obtida de apiários com acesso a Baccharis dracunculifolia (alecrim-do-campo) e a própolis marrom com acesso a Baccharis dracunculifolia (alecrim-do-campo) e Vernonia polyanthes (assa-peixe).

Para obtenção do resíduo, realizou-se a extração da própolis. Utilizou-se $30 \mathrm{~g}$ de própolis bruta triturada para cada $100 \mathrm{~mL}$ de solução hidro-alcoólica (70\%), por período de 10 dias, com posterior filtragem em papel-filtro, obtendo-se a solução-estoque (STRADIOTTI JUNIOR et al., 2004). Com a retirada do extrato se obteve o resíduo, o qual foi seco em 
estufa de circulação de ar forçada. Após a secagem, os resíduos foram triturados em moinho de facas tipo Wiley, em crivos de $2 \mathrm{~mm}$, e armazenados em sacos plásticos, em temperatura ambiente, para posterior utilização.

A atividade antimicrobiana foi avaliada com o uso de amostras bacterianas padronizadas: Escherichia coli derivada ATCC 25922, Salmonella typhymurium derivada ATCC 14028 e Klebsiella pneumoniae derivada ATCC 13883. Também foram usadas amostras de Pseudomonas aeruginosa, Staphyococcus aureus e Staphylococcus intermedius obtidas de processos infecciosos de animais, sendo estas previamente identificadas pelas suas características morfotintoriais e reações bioquímicas em meios específicos.

$\mathrm{O}$ inóculo foi preparado a partir da suspensão bacteriana em caldo infuso de cérebro e coração (caldo BHI), cuja turbidez foi ajustada, por comparação visual, ao tubo 0,5 da escala de Mac Farland (correspondente a 1,5 x $10^{8}$ bactérias $/ \mathrm{mL}$ ).

$\mathrm{Na}$ etapa seguinte foram adicionados $10 \mathrm{~mL}$ de caldo BHI em tubos de ensaio, acrescido do inóculo e dos tratamentos, cinco níveis $(0 ; 0,0625 ; 0,125 ; 0,25$; e $0,5 \mathrm{~g})$ de inclusão do resíduo da extração de própolis verde e marrom, além do controle para inóculo $(\mathrm{CI})$ somente com caldo $\mathrm{BHI}$ e $0,5 \mathrm{~g}$ de resíduo da extração de própolis, sendo incubados em estufa a $37^{\circ} \mathrm{C}$ por período de 24 horas, em condições de aerobiose. Posteriormente realizou-se a contagem bacteriana total (CBT) pela técnica de pour plate (TORTORA et al., 2005). A avaliação do efeito antimicrobiano foi realizada por meio da contagem de Unidades Formadoras de Colônias (UFC), após 48 horas de incubação, em estufa a $37^{\circ} \mathrm{C}$. Todas as análises foram realizadas em três repetições.

Os dados foram analisados por meio do teste de Qui Quadrado utilizando o pacote estatístico SISVAR, e foi realizada comparação de médias a $5 \%$ de significância.

\section{RESULTADOS E DISCUSSÃO}

A Tabela 1 apresenta os resultados obtidos em Unidade Formadora de Colônia (UFC) das bactérias Staphylococcus aureus e Staphylococcus intermedius, que são Gram-positivas. Observa-se maior efeito antimicrobiano do resíduo da extração da própolis verde sobre as bactérias $S$. aureus e $S$. intermedius. Níveis hidroalcoólicos acima de $0,25 \mathrm{~g}$ já apresentaram redução na contagem de UFC (Tabela 1), com valores abaixo de $300 \mathrm{UFC}$, considerado como limite para o crescimento bacteriano, antes do pleno crescimento (incontável).

$\mathrm{Na}$ Tabela 2, tem-se a porcentagem do total da Contagem de Unidades Formadoras de Colônias (UFC), de bactéricas Gram-positivas, sob efeito da inoculação do resíduo da própolis verde e marrom. Os resultados da porcentagem do total de UFC, das bactérias Staphylococcus aureus e Staphylococcus intermedius sugere que o resíduo da própolis verde apresentou maior efeito antimicrobiano sobre $S$. aureus e sobre $S$. intermedius, sendo as porcentagens de aparecimento de UFC acima de $>300$, e placas com número de bactérias incontável, de 33,3 e $30,6 \%$ de UFC de $S$. aureus, respectivamente para o resíduo da extração da própolis verde e da própolis marrom, e 38,9 e $19,5 \%$ de UFC de $S$. intermedius respectivamente para própolis verde e marrom. Sendo assim, o extrato da própolis verde apresenta-se com poder antimicrobiano maior e mais forte, mesmo passando por todas as etapas de extração. 
Rev. Bras. Saúde Prod. Anim., Salvador, v.17, n.1, p.65-72 jan./mar., $2016 \quad$ http://www.rbspa.ufba.br

Tabela 1. Contagem de Unidades Formadoras de Colônias (UFC), de bactérias Grampositivas (Staphylococcus aureus e Staphylococcus intermedius), em função da dose de inclusão do resíduo da extração das própolis verde e marrom

\begin{tabular}{lllllcc}
\hline \multirow{2}{*}{ Bactérias } & \multicolumn{6}{c}{ Dose de inclusão do resíduo da extração da própolis (g) } \\
\cline { 2 - 7 } & CI & 0,5 & 0,25 & 0,125 & 0,0625 & 0 (controle) \\
\hline Staphylococcus aureus & 0 & 8 & 263 & $>300$ & $>300$ & incontável \\
Staphylococcus intermedius & 0 & 52 & 283 & incontável & 90 & incontável \\
\hline & \multicolumn{7}{c}{ Própolis Marrom } \\
\hline Staphylococcus aureus & 0 & $>300$ & $>300$ & incontável & incontável & incontável \\
Staphylococcus intermedius & 0 & 146 & 217 & $>300$ & incontável & incontável \\
\hline
\end{tabular}

$\mathrm{CI}=\operatorname{com} 0,5 \mathrm{~g}$ de resíduo, sem inóculo bacteriano.

Tabela 2. Porcentagem do total da Contagem de Unidades Formadoras de Colônias (UFC), de bactérias Gram-positivas, sob efeito da inoculação do resíduo das própolis verde e marrom

\begin{tabular}{|c|c|c|c|c|c|c|}
\hline Contagem de UFC & $0-100$ & $100-200$ & $200-300$ & $>300$ & Incontável & Total \\
\hline \multicolumn{7}{|c|}{ Staphylococcus aureus } \\
\hline Própolis Verde & 16,7 & 0,0 & 16,7 & 33,3 & 0,0 & $66,7^{\mathrm{a}}$ \\
\hline Própolis Marrom & 0,0 & 2,8 & 0,0 & 13,9 & 16,7 & $33,3^{b}$ \\
\hline Total & $16,7^{\mathrm{B}}$ & $2,8^{\mathrm{C}}$ & $16,7^{\mathrm{B}}$ & $47,2^{\mathrm{A}}$ & $16,7^{\mathrm{B}}$ & 100,0 \\
\hline \multicolumn{7}{|c|}{ Staphylococcus intermedius } \\
\hline Própolis Verde & 22,2 & 0,0 & 5,6 & 22,2 & 16,7 & $66,7^{\mathrm{a}}$ \\
\hline Própolis Marrom & 2,8 & 5,6 & 5,6 & 13,9 & 5,6 & $33,3^{b}$ \\
\hline Total & $25,0^{\mathrm{B}}$ & $5,6^{\mathrm{D}}$ & $11,1^{\mathrm{C}}$ & $36,1^{\mathrm{A}}$ & $22,2^{\mathrm{B}}$ & 100,0 \\
\hline
\end{tabular}

Visto que não há trabalhos utilizando resíduo do extrato de própolis, em comparação com estudos utilizando esta etapa anterior, os resultados apresentados por Langoni et al. (1996) mostraram a eficiência do efeito do extrato alcoólico de própolis, o qual inibiu $100 \%$ do crescimento das amostras de Staphylococcus aureus testadas. Desta maneira, pode-se observar com o presente estudo, que o efeito antimicrobiano da própolis permanece, mesmo que em menor quantidade, no resíduo após extração. Resultado que pode tornar este produto potencial como aditivo na alimentação de ruminantes.

Resultados inibitórios de bactérias in vitro de agentes de mastite bovina
(Staphylococcus sp. e Streptococcus sp.) pelo extrato alcoólico de própolis, foram encontrados por Loguércio et al. (2006), sendo de 94,4\% de inibição para Staphylococcus sp. e 85,2\% de inibição para Streptococcus sp., desta forma foi possível verificar bom padrão de susceptibilidade daqueles microrganismos ao extrato de própolis. Tal fato também pode ser observado nas Tabelas 1 e 2, onde as bactérias Staphylococcus aureus e Staphylococcus intermedius mostraram-se susceptíveis ao resíduo da extração de própolis, sugerindo que o resíduo da extração ainda apresenta capacidade bactericida.

O resíduo da extração da própolis marrom apresentou maior inibição para 
$S$. intermedius somente nos tratamentos com $0,5 \mathrm{~g}$ e $0,25 \mathrm{~g}$ de resíduo, enquanto que para as outras concentrações de resíduo a atividade antimicrobiana se equiparou nas duas bactérias Grampositivas.

Na Tabela 3, está apresentada a contagem de Unidades Formadores de Colônias (UFC) das bactérias Escherichia coli, Pseudomonas, Salmonella e Klebsiella,
Gram-negativas. O resíduo da extração da própolis verde teve maior efeito inibitório na bactéria E. coli, Salmonella e Klebsiella, ao passo que para Pseudomonas não foi observado efeito antimicrobiano do resíduo da extração de própolis verde e marrom, o que já era esperado visto que esta última bactéria é considerada muito resistente.

Tabela 3. Contagem de Unidades Formadoras de Colônias (UFC), de bactérias Gramnegativas, sob efeito da inclusão do resíduo das própolis verde e marrom

\begin{tabular}{|c|c|c|c|c|c|c|}
\hline \multirow{2}{*}{ Contagem de UFC } & \multicolumn{6}{|c|}{ Níveis de inclusão do resíduo da extração da própolis (g) } \\
\hline & $\mathrm{CI}$ & 0,5 & 0,25 & 0,125 & 0,0625 & 0 (controle) \\
\hline & \multicolumn{6}{|c|}{ Própolis Verde } \\
\hline Escherichia coli & 0 & 6 & 131 & 162 & $>300$ & incontável \\
\hline Pseudomonas & 0 & incontável & incontável & incontável & incontável & incontável \\
\hline Salmonella & 0 & 4 & 67 & $>300$ & 70 & incontável \\
\hline \multirow[t]{2}{*}{ Klebsiella } & 0 & 16 & 12 & 46 & 12 & incontável \\
\hline & \multicolumn{6}{|c|}{ Própolis Marrom } \\
\hline Escherichia coli & 0 & $>300$ & $>300$ & incontável & $>300$ & incontável \\
\hline Pseudomonas & 0 & incontável & incontável & incontável & incontável & incontável \\
\hline Salmonella & 0 & 5 & 42 & $>300$ & $>300$ & incontável \\
\hline Klebsiella & 0 & 5 & 25 & 61 & 9 & incontável \\
\hline
\end{tabular}

$\mathrm{CI}=\operatorname{com} 0,5 \mathrm{~g}$ de resíduo, sem inóculo bacteriano.

Na Tabela 4, apresenta-se a porcentagem do total da Contagem de Unidades Formadoras de Colônias (UFC), de bactérias Gram-negativas, sob efeito da inoculação do resíduo das própolis verde e marrom. Observa-se efeito antimicrobiano do resíduo da extração da própolis sobre as bactérias Salmonella e Klebsiella, as quais apresentaram a maior porcentagem de contagem de UFC no nível $0-100$ UFC, com 58,3\% para Salmonella e 100,0\% para Klebsiella. Todavia, houve diferença quanto ao tipo de própolis, sendo o resíduo da extração da própolis verde mais eficaz contra o crescimento de Salmonella, enquanto que o resíduo da extração de própolis marrom foi mais eficiente contra o crescimento de Klebsiella.
Apesar da não existência de trabalhos utilizando resíduo da extração de própolis, comparando com o extrato, resultados semelhantes aos do presente estudo foram obtidos por Langoni et al. (1996), tendo grande eficácia antimicrobiana in vitro de extrato alcoólico de própolis, mostrando $91 \%$ de inibição das estirpes de E. coli testadas. Efeitos de inibição bacteriana pelo extrato da própolis também foram encontradas por Mazzuco et al. (1996), que obtiveram com a utilização de própolis em solução alcóolica, o controle de Salmonella em rações para aves com efeitos bactericidas nos sorotipos Salmonella typhimurium e $S$. enteritidis, que foram inoculados artificialmente na ração. Packer et al. (2007) também encontraram resultados 
Rev. Bras. Saúde Prod. Anim., Salvador, v.17, n.1, p.65-72 jan./mar., $2016 \quad \underline{\text { http://www.rbspa.ufba.br }}$

semelhantes, para inibição de $S$. aureus e E. coli pela própolis.

Observando o estudo o qual se apresenta, podemos concluir que a atividade antimicrobiana presente na própolis, permanece no extrato, e posteriormente no resíduo da extração da própolis, que é o resultado positivo que se busca, para utilização do mesmo na alimentação de ruminantes.

Tabela 4. Porcentagem do total da Contagem de Unidades Formadoras de Colônias (UFC), de bactérias Gram-negativas, sob efeito da inoculação do resíduo das própolis verde e marrom

\begin{tabular}{|c|c|c|c|c|c|c|}
\hline \multirow{2}{*}{ Item } & \multicolumn{5}{|c|}{ Contagem de UFC } & \multirow{2}{*}{ Total } \\
\hline & $0-100$ & $100-200$ & $200-300$ & $>300$ & Incontável & \\
\hline \multicolumn{7}{|l|}{ Escherichia coli } \\
\hline Própolis Verde & 16,7 & 27,8 & 5,6 & 16,7 & 0,0 & $66,7^{\mathrm{a}}$ \\
\hline Própolis Marrom & 0,0 & 0,0 & 0,0 & 25,0 & 8,3 & $33,3^{b}$ \\
\hline Total & $16,7^{\mathrm{C}}$ & $27,8^{\mathrm{B}}$ & $5,6^{\mathrm{E}}$ & $41,7^{\mathrm{A}}$ & $8,3^{\mathrm{D}}$ & 100,0 \\
\hline \multicolumn{7}{|l|}{ Pseudomonas } \\
\hline Própolis Verde & 0,0 & 0,0 & 0,0 & 0,0 & 66,7 & $66,7^{\mathrm{a}}$ \\
\hline Própolis Marrom & 0,0 & 0,0 & 0,0 & 0,0 & 33,3 & $33,3^{b}$ \\
\hline Total & $0,0^{\mathrm{B}}$ & $0,0^{\mathrm{B}}$ & $0,0^{\mathrm{B}}$ & $0,0^{\mathrm{B}}$ & $100,0^{\mathrm{A}}$ & 100,0 \\
\hline \multicolumn{7}{|l|}{ Salmonella } \\
\hline Própolis Verde & 19,4 & 0,0 & 0,0 & 13,9 & 0,0 & $33,3^{b}$ \\
\hline Própolis Marrom & 38,9 & 0,0 & 0,0 & 27,8 & 0,0 & $66,7^{\mathrm{a}}$ \\
\hline Total & $58,3^{\mathrm{A}}$ & $0,0^{\mathrm{C}}$ & $0,0^{\mathrm{C}}$ & $41,7^{\mathrm{B}}$ & $0,0^{\mathrm{C}}$ & 100,0 \\
\hline \multicolumn{7}{|l|}{ Klebsiella } \\
\hline Própolis Verde & 66,7 & 0,0 & 0,0 & 0,0 & 0,0 & $66,7^{\mathrm{a}}$ \\
\hline Própolis Marrom & 33,3 & 0,0 & 0,0 & 0,0 & 0,0 & $33,3^{\mathrm{b}}$ \\
\hline Total & $100,0^{\mathrm{A}}$ & $0,0^{\mathrm{B}}$ & $0,0^{\mathrm{B}}$ & $0,0^{\mathrm{B}}$ & $0,0^{\mathrm{B}}$ & 100,0 \\
\hline
\end{tabular}

Não houve efeito do resíduo da extração de própolis verde ou marrom sobre o crescimento de bactérias gênero Pseudomonas.

Os efeitos da inoculação do resíduo da extração das própolis verde e marrom sugerem maior eficácia sobre as bactérias Gram-positivas (Tabelas 1 e 2) e menor eficiência ou mesmo ineficácia sobre as bactérias Gram-negativas (Tabelas 3 e 4).

Machado et al. (2008) verificaram que as concentrações de extrato de própolis demonstraram atividade antimicrobiana para Staphylococcus coagulase positiva (bactéria Gram-positiva), e que tal extrato pode ser usado em medicamentos para tratar otite canina.

Os resíduos da extração hidroalcoólica de própolis verde e marrom atuaram como inibidores de crescimento das bactérias Staphylococcus aureus, Staphylococcus intermedius, Escherichia coli, Salmonella e Klebsiella. Portanto, com este resultado positivo, conclui-se que o resíduo pode ser utilizado na alimentação de ruminantes como aditivo, devido à sua ação antimicrobiana, acarretando melhorias no desempenho dos animais.

Ainda assim, outros estudos devem ser feitos para abordar tal efeito antimicrobiano do resíduo da extração 
das própolis verde e marrom para outras bactérias importantes principalmente para a patogenia dos animais.

\section{REFERÊNCIAS}

GONSALES, G.Z.; ORSI, R.O.; FERNANDES JUNIOR, A.; RODRIGUES, P.; FURANI, S.R.C. Antibacterial activity of propolis collected in different regions of Brazil. Journal of Venomous Animals and Toxins including Tropical Diseases, v.12, n.2, p.276-284, 2006.

ÍTAVO C.C.B.F.; MORAIS M.G.; COSTA C.; ÍTAVO L.C.V.; FRANCO G.L.; SILVA J.A.; REIS F.A. Addition of propolis or monensin in the diet: Behavior and productivity of lambs in feedlot. Animal Feed Science and Technology, v.165, p.161-166, 2011.

LANGONI, H.; DOMINGUES, P.F.; FUNARI, S.R.C.; CHANDE, C.G.; NEVES, I.R. Efeito antimicrobiano "in vitro" da própolis. Arquivo Brasileiro de Medicina Veterinária e Zootecnia, v.48, p.227-229, 1996.

LOGUÉRCIO, A.P.; GROFF, A.N.M.; PEDROZZO, A.F.; WITT, N.M.; SILVA, M.S.; VARGAS, A.C. Atividade in vitro do extrato de própolis contra agentes bacterianos da mastite bovina. Pesquisa Agropecuária Brasileira, v.41, n.2, p.347-349, 2006.

LONGHINI, R.; RAKSA, S.M.; OLIVEIRA, A.C.P.; SVIDZINSKI, T.I.E.; FRANCO, S.L. Obtenção de extratos de própolis sob diferentes condições e avaliação de sua atividade antifúngica. Revista Brasileira de Farmacognósia, v.7, n.2, p.388-395, 2007.
MACHADO, G.; CARDOSO, R.L.; MABONI, F.; VARGAS, A.C.

Atividade antimicrobiana do extrato de própolis frente a isolados de Staphylococcus coagulase positiva de otite canina. In: CONBRAVET CONGRESSO BRASILEIRO DE MEDICINA VETERINÁRIA, 35., 2008, Gramado, RS. Anais... Gramado, RS, 2008.

MAZZUCO, H.; SILVA, R.D.M.; BERCHIERI, J.R.A.; OLIVEIRA, E. Utilização da própolis e álcool etílico no controle de Salmonella em rações avícolas. Scientia Agricola, v.53, n.1, p.1-7, 1996.

MIRZOEVA, O.K.; GRISHANIN, R.N.; CALDER, P.C. Antimicrobial action of propolis and some of its components: the effects on growth, membrane potential and motility of bacteria. Microbiological Research, v.152, p.239-246, 1997.

PACKER, J.F.; LUZ, M.M.S. Método para avaliação e pesquisa da atividade antimicrobiana de produtos de origem natural. Revista Brasileira de Farmacognosia, v.17, n.1, p.102-107, 2007.

PARK, Y.K.; IKEGARI, M.; ABREU, J.A.S.; ALCICI, M.N.F. Estudo da preparação dos extratos de própolis e suas aplicações. Ciência e Tecnologia de Alimentos, v.18, n.3, p.313-318, 1998.

SHALMANY, S.K.; SHILVAZAD, M. The effect of diet propolis supplementation on Ross broiler chicks performance. International Journal of Poultry Science, v.5, n.1, p.84-88, 2006. 
STRADIOTTI JUNIOR, D.;

QUEIROZ, A.C.; LANA, R.P.;

PACHECO, C.G.; EIFERT, E.C.;

NUNES, P.M.M. Ação da própolis

sobre a desaminação de aminoácidos e a

fermentação ruminal. Revista

Brasileira de Zootecnia, v.33, n.4, p.1086-1092, 2004.

TORTORA, G.J.; FUNKE, B.R.; CASE, C.L. Microbiologia. 8.ed. SãoPaulo:

Artmed, 2005.

VARGAS, A.C.; LOGUERCIO, A.P.; WITT, N.M.; COSTA, M.M.; SILVA, M.S.; VIANA, L.R. Atividade antimicrobiana "in vitro" de extrato alcoólico de própolis. Ciência Rural, v.34, n.1, p.159-163, 2004.

Data de recebimento: 07/04/2015

Data de aprovação: 10/03/2016 